\title{
Clinical Trial of Combining Botulinum Toxin Injection and Fissurectomy for Chronic Anal Fissure: A Dose-Dependent Study
}

\author{
Nuha Alsaleh, Abdullah I. Aljunaydil, Gaida A. Aljamili \\ Division of General Surgery, Department of Surgery, College of Medicine and King Saud University Medical City, King Saud University, \\ Riyadh, Saudi Arabia
}

Purpose: Our aim was to evaluate the effectiveness of combining a fissurectomy with a botulinum toxin A injection in treating chronic anal fissure.

Methods: A single surgeon in Saudi Arabia conducted a nonrandomized prospective cohort study between October 2015 and July 2020. The cohort included 116 female patients with chronic anal fissures with a mean age of $36.57 \pm 11.52$ years who have presented to the surgical outpatient clinic and received a botulinum toxin injection A combined with fissurectomy. They were followed up with for at least 1,2,3,4, and 8 weeks to evaluate the effects of the treatment, then again at 1 year. Primary outcome measures were symptomatic relief, complications, recurrence, and the need for further surgical intervention.

Results: Treatment with botulinum toxin A combined with fissurectomy was effective in $99.1 \%$ of patients with chronic anal fissure at 1 year. Five patients experienced recurrences at 8 weeks which resolved completely with a pharmacological sphincterotomy. Twelve patients experienced minor incontinence which later disappeared. Pain completely disappeared in more than half of the patients (55.2\%) within 7 to 14 days. Pain started to improve in less than 8 days among patients treated with a dose of $50 \pm 10 \mathrm{IU}(\mathrm{P}=0.002)$.

Conclusion: Seventy units of botulinum toxin A injection combined with a fissurectomy is a suitable second-line treatment of choice for chronic anal fissure, with a high degree of success and low rate of major morbidity.

Keywords: Fissure in ano; Chronic disease; Botulinum toxins; Sphincterotomy

\section{INTRODUCTION}

Anal fissure is a common surgical disease in which spasms of the internal anal sphincter play a major role. It is usually treated conservatively. The golden surgical treatment is a lateral internal sphincterotomy, yet it carries the potential risk of developing

Received: Mar 24, 2021 • Revised: Jun 132021 - Accepted: Jul 27, 2021

Correspondence to: Nuha Alsaleh, M.D.

Division of General Surgery, Department of Surgery, College of Medicine and King Saud University Medical City, King Saud University, P.0. Box: 11576, Riyadh 7891, Saudi Arabia

Tel: +966-55-277-9202, Fax: +966-55-032-2828

E-mail:dr.nuhaalsaleh@gmail.com

ORCID: https://orcid.org/0000-0003-2934-1565

(C) 2021 The Korean Society of Coloproctology

This is an open-access article distributed under the terms of the Creative Commons Attribution NonCommercial License (https://creativecommons.org/licenses/by-nc/4.0) which permits unrestricted noncommercial use, distribution, and reproduction in any medium, provided the original work is properly cited. postoperative complications in terms of gas or stool incontinence $[1,2]$. Therefore, another treatment was recently introduced: botulinum toxin A (BTA) injection in conjunction with a fissurectomy $[3,4]$. In this study, we aim to evaluate the efficacy of the BTA injection and fissurectomy for treating chronic anal fissures. We subdivided the doses and the groups according to the subjective feeling of sphincter tightness into 3 different groups with 3 different doses of BTA. All participants in the General Surgery division gave informed consent and received a full description of the research. Participation was voluntary and the approval from Institutional Review Board (IRB) of King Saud University Medical City was obtained (No. IRB-k1983750).

\section{METHODS}

This case series is a prospective study (a nonrandomized simple sampling). A total of 116 patients who have presented to the sur- 
gical outpatient clinic of King Saud University Medical City (Riyadh, Saudi Arabia) with anal fissure between October 2015 and July 2020 were enrolled. Inclusion criteria consisted of all patients with evidence of a posterior or anterior fissure with clinical evidence of an increase in anal resting tone per physical exam. We excluded pediatric patients and all females that were at high risk of problems, particularly after obstetric operations and deliveries; also, these females' sphincters and muscle tone were very weak, and therefore unable to tolerate surgery. This could also affect their healing and muscle tone later. Persistent symptoms included pain and bleeding after defecation for more than 8 weeks despite conservative treatment. Other exclusion criteria included patients with anal abscesses or fistulas; those with fissures associated with different pathologies such as inflammatory bowel disease, concomitant medication that could interfere with BTA such as aminoglycosides, baclofen, or diazepam; and pregnant women.

The study's endpoint was the evaluation of complete healing after BTA injection combined with fissurectomy and comparing dose-dependent efficacy and complications between varying doses of 50 units, 70 units, and 100 units. The treatment was considered successful if the patient experienced an absence of symptoms. A secondary variable was the latency of the effect, which was defined by considering the interval of time between the day of treatment and the start of symptomatic relief follow-up, and rate of incontinence and time of resolving (days), linked to different doses of BTA (50 units vs. 70 units vs. 100 units).

The Ministry of Health Public IRB of Saudi Arabia approved this study (No. 493875097). All appropriate patient consent forms were obtained.

\section{Baseline assessment and operative technique}

All patients underwent a pre-treatment evaluation, including a clinical examination. Each patient received conservative treatment (sitz bath, stool softener, and pharmacological treatment [diltiazem]), and underwent the same evaluation as performed at baseline. One surgeon (Alsaleh N) operated on all of the patients.

The procedure was performed as a day-case, under laryngeal mask anesthesia, with the patient lying in the lithotomy position. One hundred units of botulinum neurotoxin A (BoNT/A; Botox, Allergan, Dublin, UK) were diluted with $1 \mathrm{~mL}$ of normal saline. The solution was injected into the internal anal sphincter using a small 27-gauge needle. The injection was divided in half, as is standard; half of the amount was administered between 3 oclock and 9 oclock, and the other half was administered either at or around the fissure. However, the amount of BTA varied; patients received 50, 70, or 100 units. The fissurectomy occurred in each patient with a sharp by removing the fibrotic fissure edges and unhealthy granulation tissue at the base.

\section{Clinical care, follow-up, and outcome measures}

All patients were sent home on laxatives and oral analgesia within 24 hours of the procedure. Patients were advised to take regular warm sitz baths, maintain a high-fiber diet, and increase their fluid intake.

All patients were evaluated in the outpatient clinic at approximately 7, 14, 21, and 28 days, and at 8 weeks postoperative. Symptoms were reviewed in terms of pain (degree of improvement and onset of improvement), per rectal bleeding, and presence of incontinence (gas, liquid, or stool). We followed up with the healed patients for 1 year, during which time they underwent historical and physical examinations.

\section{Statistical analysis}

The paper conducts a statistical analysis using IBM SPSS Statistics ver. 26 (IBM Corp., Armonk, NY, USA), where descriptive and frequency analyses are calculated first. The paper then proceeds to recode some of the continuous variables, such as age, into categorical variables in order to ensure the chi-square analysis is conducted efficiently. The paper will then proceed with the chisquare analysis, where several groups' relationships are tested under a $95 \%$ confidence interval. The null hypothesis was rejected if the obtained $\mathrm{P}$-value from the chi-square analysis was greater than the critical alpha level of 0.05 .

\section{RESULTS}

The BoNT/A dose units were divided into 3 categories: $50 \pm 10$, $70 \pm 10$, and $>80$. The analysis in Table 1 reveals that participants whose dose was greater than 80 units were old age. Analysis of the categorical data further reveals that those in the group between 41 and 60 years of age who also received 40 to 60 units of BoNT/A $(\mathrm{n}=42,36.5 \%)$, while the group above 60 years who also received BoNT/A greater than 80 units had the lowest frequency $(n=1$, $0.9 \%$ ). Cross-tabulation between the location of the fissure and the BoNT/A units indicates that those with a posterior fissure who also received between 61 and 80 units of BoNT/A had the highest frequency $(n=40,34.5 \%)$, while the group with an anterior fissure who also received more than 80 units of BoNT/A had the lowest frequency $(\mathrm{n}=1,0.9 \%)$.

Table 2 shows a summary of the chi-square analysis conducted between the age categories and the time of resolving the symptoms. The obtained P-value from the analysis, 0.42 , is greater than the critical alpha level of 0.05 . Hence, the null hypothesis that there was no statistically significant difference between the 2 groups was accepted. There was no relationship between the time of resolving the symptoms and the patient's age in years.

Table 3 shows a summary of the relationship between the BoNT/A dose and the time the pain started to improve, i.e., the time it took for the symptoms to disappear entirely along with the duration of incontinence. From the results, the number of days after the pain started to improve was separated into 2 categories: less than 8 days and more than or equal to 8 days. The obtained $\mathrm{P}$-value from the chi-square analysis, 0.002 , was less than the critical alpha of 0.05 . Essentially, the number of days before the pain 
Table 1. Demographic and clinical characteristics of patients

\begin{tabular}{|c|c|c|c|c|}
\hline \multirow{2}{*}{ Characteristic } & \multirow{2}{*}{ Total } & \multicolumn{3}{|c|}{ BTA dose (unit) } \\
\hline & & $50 \pm 10$ & $70 \pm 10$ & $>80$ \\
\hline Female sex & $116(100)$ & $46(39.7)$ & $56(48.3)$ & 14 (12.1) \\
\hline Mean age (yr) & & $38.00 \pm 12.45$ & $35.54 \pm 11.21$ & $42.62 \pm 12.83$ \\
\hline \multicolumn{5}{|l|}{ Age $(y r)$} \\
\hline$>20, \leq 40$ & $46(40.0)$ & 27 (23.5) & $17(14.8)$ & $2(1.7)$ \\
\hline$>41, \leq 60$ & $56(48.7)$ & $42(36.5)$ & $12(10.4)$ & $2(1.7)$ \\
\hline$>60$ & $14(12.06)$ & $5(4.3)$ & $8(6.9)$ & $1(0.9)$ \\
\hline \multicolumn{5}{|l|}{ Location of fissure } \\
\hline Posterior & 83 (71.6) & 34 (29.3) & $40(34.5)$ & $9(7.8)$ \\
\hline Anterior & $33(28.4)$ & $7(6.0)$ & $4(3.4)$ & $1(0.9)$ \\
\hline Posterior and anterior & 20 (17.2) & $5(4.3)$ & $12(10.3)$ & $3(2.6)$ \\
\hline Postoperative diltiazem & $1(0.9)$ & $0(0)$ & $1(0.9)$ & $0(0)$ \\
\hline Yes & $2(1.7)$ & $0(0)$ & $2(1.7)$ & $0(0)$ \\
\hline No & $2(1.7)$ & $2(1.7)$ & $0(0)$ & $0(0)$ \\
\hline
\end{tabular}

Values are presented as number (\%) or mean \pm standard deviation.

BTA, botulinum toxin A.

Table 2. Correlation between age and time of resolution of symptoms

\begin{tabular}{|c|c|c|c|c|c|c|}
\hline \multirow{2}{*}{ Age (yr) } & \multicolumn{4}{|c|}{ Time (day) } & \multirow{2}{*}{$\chi^{2}$} & \multirow{2}{*}{ P-value } \\
\hline & $<7(n=9)$ & $\geq 7, \leq 14(n=64)$ & $>14, \leq 21(n=4)$ & $>21(n=39)$ & & \\
\hline$>20, \leq 40$ & $5(4.3)$ & 45 (38.8) & $3(2.6)$ & $21(18.1)$ & 6.0 & 0.42 \\
\hline$>41, \leq 60$ & $4(3.4)$ & $17(14.7)$ & $0(0)$ & 15 (12.9) & & \\
\hline$>60$ & $0(0)$ & $2(1.7)$ & $1(0.86)$ & $3(2.6)$ & & \\
\hline
\end{tabular}

Values are presented as number (\%).

Table 3. Correlation between BTA dose and the time pain starts to improve and completely disappears in terms of 7, 14, 21, and 28 days

\begin{tabular}{|c|c|c|c|c|c|}
\hline \multirow{2}{*}{ Variable } & \multicolumn{3}{|c|}{ BTA dose (unit) } & \multirow{2}{*}{$\chi^{2}$} & \multirow{2}{*}{ P-value } \\
\hline & $50 \pm 10(n=46)$ & $70 \pm 10(n=57)$ & $100(n=13)$ & & \\
\hline Time after the pain start to improve (day) & & & & 20.69 & $0.002^{*}$ \\
\hline$<8(\mathrm{n}=76)$ & $42(36.2)$ & $39(33.6)$ & $7(6.0)$ & & \\
\hline$\geq 8(n=34)$ & $4(3.4)$ & $17(14.7)$ & $7(6.0)$ & & \\
\hline Time after the pain completely disappears (day) & & & & 2.60 & 0.857 \\
\hline$<7(n=9)$ & $4(3.4)$ & $5(4.3)$ & $0(0)$ & & \\
\hline$\geq 7, \leq 14(n=64)$ & $27(23.3)$ & $29(25.0)$ & $8(6.9)$ & & \\
\hline$>14, \leq 21(n=3)$ & $1(0.9)$ & $2(1.7)$ & $0(0)$ & & \\
\hline$>21(n=40)$ & $14(12.1)$ & $20(17.2)$ & $6(5.2)$ & & \\
\hline Time of incontinence (day) & & & & 6.75 & 0.15 \\
\hline 7 & $5(17.9)$ & $8(28.6)$ & $4(14.3)$ & & \\
\hline 30 & $7(25.0)$ & $1(3.6)$ & $2(7.2)$ & & \\
\hline 90 & $0(0)$ & $1(3.6)$ & $0(0)$ & & \\
\hline
\end{tabular}

Values are presented as number (\%).

BTA, botulinum toxin A.

${ }^{*} \mathrm{P}<0.05$ at $95 \%$ confidence interval. 
Table 4. Correlation between incontinence and location of the fissure, age, BTA dose

\begin{tabular}{|c|c|c|c|c|c|}
\hline & \multicolumn{3}{|c|}{ Incontinence } & \multirow{2}{*}{$\chi^{2}$} & \multirow{2}{*}{ P-value } \\
\hline & No $(n=86)$ & Gas $(n=10)$ & Liquid $(n=13)$ & & \\
\hline Location of fissure & & & & 9.89 & 0.13 \\
\hline Posterior & $62(53.4)$ & $13(11.2)$ & $8(6.9)$ & & \\
\hline Anterior & $9(7.8)$ & $0(0)$ & $3(2.6)$ & & \\
\hline Posterior and anterior & $15(12.9)$ & $3(2.6)$ & $2(1.7)$ & & \\
\hline Age (yr) & & & & 4.72 & 0.32 \\
\hline$>20, \leq 40$ & $58(50.4)$ & $9(7.8)$ & $7(6.0)$ & & \\
\hline$>41, \leq 60$ & $25(21.7)$ & $5(4.3)$ & $6(5.2)$ & & \\
\hline$>60$ & $3(2.6)$ & $0(0)$ & $0(0)$ & & \\
\hline BTA dose (unit) & & & & 5.22 & 0.27 \\
\hline $50 \pm 10$ & $32(27.6)$ & $7(6.0)$ & $7(6.0)$ & & \\
\hline $70 \pm 10$ & $46(39.7)$ & $6(5.2)$ & $4(3.4)$ & & \\
\hline$>80$ & $8(6.9)$ & $4(3.4)$ & $2(1.7)$ & & \\
\hline
\end{tabular}

Values are presented as number (\%).

BTA, botulinum toxin $A$.

started to improve was dependent on the amount of BoNT/A units administered. The number of days after the pain completely disappeared was divided into 4 categories: $<7$ days $(n=9), \geq 7$ and $\leq 14$ days $(n=64),>14$ and $\leq 21$ days $(n=3)$, and $>21$ days $(n=40)$. The obtained P-value, 0.857 , was greater than the critical alpha level of 0.05 . Hence, there was no relationship between the number of days after the pain completely disappeared and the amount of BoNT/A units administered. For the duration of incontinence, the obtained $\mathrm{P}$-value of 0.15 revealed no significant relationship with the amount of BoNT/A units administered.

The number of days after which the pain completely disappeared was also divided into 4 categories. The results indicate that the largest group $(n=6,55.2 \%)$ took between 8 and 14 days for the pain to completely disappear while the second group $(n=40$, $34.5 \%)$ took more than 21 days. The remaining results were as follows: $<7$ days [7.8\%], $\geq 7$ and $\leq 14$ days [55.2\%], $>14$ and $\leq 21$ days [2.6\%], and $>21$ days [34.5\%].

Table 4 reveals a summary of the obtained chi-square analysis between incontinence and location of the fissure, age, and BoNT/ A dose. From the analysis, it is clear that all of the obtained P-values were greater than the critical alpha level of 0.05 . Hence, there was a statistically significant relationship between incontinence and location of the fissure, age, and BoNT/A dose.

\section{DISCUSSION}

The treatment of anal fissures was chaotic until 1951 when Eisenhammer proposed using a partial lateral internal sphincterotomy. It is considered the standard treatment for anal fissures [5]. However, owing to the noticeable risk of permanent fecal incontinence (1\% of patients) which may occur many years after if the sphinc- ter is exposed to further damage such as a complicated delivery or anal surgery [6].

Since the BTA injection was introduced as a potential treatment for anal fissures in 1993, there were several studies that prove its efficacy with a variable healing rate and recurrent rate [6-8]. The BTA works by inhibiting acetylcholine release into the internal sphincter close to an anal fissure [7]; on the other hand, a fissurectomy alone is advocated for in children and adults in some areas [9]. It enhances healing by removing the fibrotic fissure edges; nevertheless, it does not address the anal sphincter hypertonicity. There are various studies that describe how combining a fissurectomy and BTA achieve an excellent healing rate of $79 \%$ after 1 year [10].

We decided to conduct a study of all females since they have a higher rate of incontinence [11] resulting from risk factors during pregnancy and childbirth. Eighty-four of our patients $(72.4 \%)$ displayed posterior fissures and 15 patients $(12.9 \%)$ had anterior fissures. This is consistent with what is reported in the literature, in which $90 \%$ of all fissures occurred posteriorly, $10 \%$ anteriorly, and less than $1 \%$ of patients had both anterior and posterior fissures [12-14]. However, we had a higher number of patients $(n=17)$ who had both anterior and posterior fissures than reported in the literature.

In comparison with Barnes et al. [15], who used a similar technique of combining fissurectomy and BoNT/A, our study has a larger number of patients. We were able to achieve an overall healing rate of $99.1 \%$ at 1 year without resorting to a surgical sphincterotomy. There was only one recurrence in the 1-year follow-up, a figure slightly more favorable to Barnes et al. [15]. It is noteworthy to recognize that they used 100 units in all patients, using a technique where they injected into the base of the fissure; 
whereas we injected half of the amount at the fissure and the other half at 3 oclock and 9 oclock. We believe this relaxes the whole sphincter, which could attribute to a more success rate.

There is a considerable variation in the literature in regards to the most effective site of BTA injection. Our technique is similar to what was reported in the previous study [16], where they used only 25 units and the healing rate after BoNT/A injection was $81.8 \%$. In comparison to our data, injecting patients with a higher dose of BoNT/A (i.e., 100 units) fails to have superior results in terms of shortening the time for symptoms' resolution neither the onset when compared to 50 or 70 units where all happen $>7$ days $87.0 \%$ vs. $83.9 \%$ vs. $85.7 \%$ for 50,70 , and 100 units of BoNT/A groups, respectively. Noteworthy is the fact that there was a higher incidence of liquid incontinence in the group that received 100 units. Our study reported a $10.3 \%$ degree of incontinence in the immediate postoperative period. This appears to be on the upper limit of the range reported $(4 \%-7 \%)$ in previous studies $[5,14$, 17], which likely attributes to the technique of injecting in 3 areas. However, the incontinence was transient, and all patients reported normal continence by the 8-week follow-up.

In our data, when we compare the 3 groups (50, 70, and 100 units), there were superior results with the use of 70 units with complete resolution of symptoms at $76.7 \%$ in 7 - to 14 -days compared with no incontinence at a rate of $82.1 \%$ even though Bobkiewicz et al.s [18] meta-analysis claims no dose-dependent efficiency.

In our experience, we likely had more success because all of our patients were female. Soltany et al. [16] identified the superiority of the results in females. Our results compare favorably with published data. Most of the enrolled patients (94.8\%) resolved their symptoms and had complete healing of the fissure(s). Only one recurrence occurred after achieving complete healing, and this particular patient revealed later they did not comply with conservative therapy or good eating habits.

There were 5 recurrences in a mean follow-up period of 8 weeks. These were completely resolved by using diltiazem.

In conclusion, 70 units of BTA injection combined with a fissurectomy is a suitable second-line treatment for a chronic idiopathic anal fissure that is not associated with other anal conditions. Due to the high degree of success and low rate of major morbidity, the procedure may be considered as a straightforward, safe, and effective treatment for anal fissures.

\section{CONFLICT OF INTEREST}

No potential conflict of interest relevant to this article was reported.

\section{REFERENCES}

1. García-Aguilar J, Belmonte Montes C, Perez JJ, Jensen L, Madoff $\mathrm{RD}$, Wong WD. Incontinence after lateral internal sphincteroto- my: anatomic and functional evaluation. Dis Colon Rectum 1998; 41:423-7.

2. Hsu TC, MacKeigan JM. Surgical treatment of chronic anal fissure. A retrospective study of 1753 cases. Dis Colon Rectum 1984; 27:475-8.

3. Jankovic J, Brin MF. Therapeutic uses of botulinum toxin. N Engl J Med 1991;324:1186-94.

4. Jones OM, Moore JA, Brading AF, Mortensen NJ. Botulinum toxin injection inhibits myogenic tone and sympathetic nerve function in the porcine internal anal sphincter. Colorectal Dis 2003;5: 552-7.

5. Nelson RL, Chattopadhyay A, Brooks W, Platt I, Paavana T, Earl S. Operative procedures for fissure in ano. Cochrane Database Syst Rev 2011;2011:CD002199.

6. Menteş BB, Irkörücü O, Akin M, Leventoğlu S, Tatlicioğlu E. Comparison of botulinum toxin injection and lateral internal sphincterotomy for the treatment of chronic anal fissure. Dis Colon Rectum 2003;46:232-7.

7. Jost WH, Schimrigk K. Use of botulinum toxin in anal fissure. Dis Colon Rectum 1993;36:974.

8. Iswariah H, Stephens J, Rieger N, Rodda D, Hewett P. Randomized prospective controlled trial of lateral internal sphincterotomy versus injection of botulinum toxin for the treatment of idiopathic fissure in ano. ANZ J Surg 2005;75:553-5.

9. Zeitoun JD, Blanchard P, Fathallah N, Benfredj P, Lemarchand N, de Parades V. Long-term outcome of a fissurectomy: a prospective single-arm study of 50 operations out of 349 initial patients. Ann Coloproctol 2018;34:83-7.

10. Scholz T, Hetzer FH, Dindo D, Demartines N, Clavien PA, Hahnloser D. Long-term follow-up after combined fissurectomy and Botox injection for chronic anal fissures. Int J Colorectal Dis 2007;22:1077-81.

11. Landefeld CS, Bowers BJ, Feld AD, Hartmann KE, Hoffman E, Ingber MJ, et al. National Institutes of Health state-of-the-science conference statement: prevention of fecal and urinary incontinence in adults. Ann Intern Med 2008;148:449-58.

12. Lund JN, Scholefield JH. Aetiology and treatment of anal fissure. Br J Surg 1996;83:1335-44.

13. Schouten WR, Briel JW, Auwerda JJ, De Graaf EJ. Ischaemic nature of anal fissure. Br J Surg 1996;83:63-5.

14. Kodner IJ, Fry RD, Fleshman JW, Birnbaum EH, Read TE. Colon, rectum and anus. In: Schwartz SI, editor. Principles of surgery. 7th ed. New York: Mac Grow-Hill; 1999. p. 1265-382.

15. Barnes TG, Zafrani Z, Abdelrazeq AS. Fissurectomy combined with high-dose botulinum toxin is a safe and effective treatment for chronic anal fissure and a promising alternative to surgical sphincterotomy. Dis Colon Rectum 2015;58:967-73.

16. Soltany S, Hemmati HR, Toussy JA, Salehi D, Toosi PA. Therapeutic properties of botulinum toxin on chronic anal fissure treatment and the patient factors role. J Family Med Prim Care 2020;9:1562-6.

17. Richard CS, Gregoire R, Plewes EA, Silverman R, Burul C, Buie D, 


\section{Coloproctology Nuha Alsalen, et al.}

et al. Internal sphincterotomy is superior to topical nitroglycerin in the treatment of chronic anal fissure: results of a randomized, controlled trial by the Canadian Colorectal Surgical Trials Group. Dis Colon Rectum 2000;43:1048-57.
18. Bobkiewicz A, Francuzik W, Krokowicz L, Studniarek A, Ledwosiński W, Paszkowski J, et al. Botulinum toxin injection for treatment of chronic anal fissure: is there any dose-dependent efficiency? A meta-analysis. World J Surg 2016;40:3064-72. 